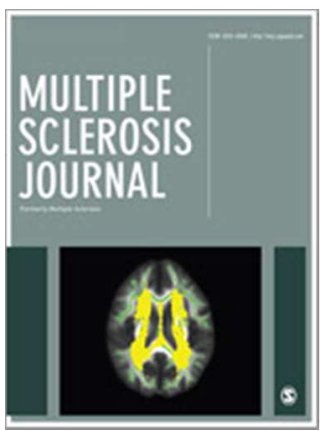

\title{
Ethnicity and Prevalence of Multiple Sclerosis in East London
}

\begin{tabular}{|c|c|}
\hline Journal: & Multiple Sclerosis Journal \\
\hline Manuscript ID & MSJ-15-0720.R3 \\
\hline Manuscript Type: & Original Research Paper \\
\hline Date Submitted by the Author: & 20-Feb-2016 \\
\hline Complete List of Authors: & $\begin{array}{l}\text { Albor, Christo; Queen Mary University of London, Neuroscience and } \\
\text { Trauma } \\
\text { Du Sautoy, Timothy; Queen Mary University of London, Neuroscience and } \\
\text { Trauma } \\
\text { Kali Vanan, Narmadha; Queen Mary University of London, Neuroscience } \\
\text { and Trauma } \\
\text { Turner, Ben; Queen Mary University of London, Neuroscience and Trauma; } \\
\text { Royal London Hospital, Neurology } \\
\text { Boomla, Kambiz; Queen Mary University of London, Centre for Primary } \\
\text { Care and Public Health } \\
\text { Schmierer, Klaus; Queen Mary University of London, Neuroscience and } \\
\text { Trauma; Royal London Hospital, Neurology }\end{array}$ \\
\hline Keywords: & Epidemiology, Multiple sclerosis, Ethnicity, London \\
\hline Abstract: & $\begin{array}{l}\text { Background: Incidence and prevalence rates of Multiple Sclerosis (MS) are } \\
\text { generally higher in White populations than other ethnic groups. Relevant } \\
\text { studies in the United Kingdom (UK) were conducted over } 30 \text { years ago. } \\
\text { Objectives: The aim of this study is to provide updated ethnicity-specific } \\
\text { MS prevalence rates in the UK. } \\
\text { Methods: Electronic records from general practices in four east London } \\
\text { boroughs were queried for the number of MS-diagnosed patients, grouped } \\
\text { by ethnicity, into } 5 \text {-year age bands. Compared against total registered GP } \\
\text { patients in the area (c. } 900,000 \text { ), the age-standardised MS prevalence was } \\
\text { calculated by ethnic group. } \\
\text { Results: The overall age-standardised prevalence of MS was } 111 \text { per } \\
100,000 \text { ( } 152 \text { for women, } 70 \text { for men), and } 180,74 \text {, and } 29 \text { for the White, } \\
\text { Black and South Asian populations, respectively. The sex ratios }\end{array}$ \\
\hline
\end{tabular}


Conclusion: MS prevalence was considerably lower amongst Black and South Asian populations, compared to the White population, by $59 \%$ and $84 \%$ respectively. However, compared to available data in Africa and South Asia, MS is several times more prevalent among Black people and South Asians living in the UK than their territorial ancestry. 


\title{
Ethnicity and Prevalence of Multiple Sclerosis in East London
}

\author{
Christo Albor ${ }^{1}$, Timothy du Sautoy ${ }^{1}$, Narmadha Kali Vanan ${ }^{1}$, Ben Turner ${ }^{1,2}$, Kambiz \\ Boomla $^{1}$, and Klaus Schmierer ${ }^{1,2}$ \\ ${ }^{1}$ Blizard Institute (Neuroscience), Queen Mary University of London, London, UK \\ ${ }^{2}$ The Royal London Hospital, Barts Health NHS Trust, London, UK \\ Corresponding Author: \\ Klaus Schmierer \\ Blizard Institute \\ 2 Newark Street, Room 2.05 \\ London \\ E1 2AT
}

$\underline{\text { Keywords: }}$

Multiple Sclerosis

Epidemiology

Neuroepidemiology

Ethnicity

Minorities

Prevalence

London

United Kingdom 
Figure 1. Map of London showing borough boundaries with 'east London' catchment area highlighted.

Figure 2. Ethnicity-specific MS Prevalence: Crude (white bars) and Age-Standardised (filled bars).

Figure 3. MS Prevalence for Women by Age, Stratified by Ethnicity.

Figure 4. MS Prevalence for Men by Age, Stratified by Ethnicity. 


\begin{abstract}
Background: Incidence and prevalence rates of Multiple Sclerosis (MS) are generally higher in White populations than other ethnic groups. Relevant studies in the United Kingdom (UK) were conducted over 30 years ago.
\end{abstract}

Objectives: The aim of this study is to provide updated ethnicity-specific MS prevalence rates in the UK.

Methods: Electronic records from general practices in four east London boroughs were queried for the number of MS-diagnosed patients, grouped by ethnicity, into 5year age bands. Compared against total registered GP patients in the area (c. $900,000)$, the age-standardised MS prevalence was calculated by ethnic group.

Results: The overall age-standardised prevalence of MS was 111 per 100,000 (152 for women, 70 for men), and 180, 74, and 29 for the White, Black and South Asian populations, respectively. The sex ratios (female:male) were 2.2:1, 2.1:1 and 2.8:1 respectively.

Conclusion: MS prevalence was considerably lower amongst Black and South Asian populations, compared to the White population, by $59 \%$ and $84 \%$ respectively. However, compared to available data in Africa and South Asia, MS is several times more prevalent among Black people and South Asians living in the UK than their territorial ancestry. 


\section{Background}

Multiple sclerosis (MS) is an inflammatory demyelinating and neurodegenerative disease of the central nervous system. It is the most common chronic non-traumatic cause of disability in young adults, with a current prevalence rate in the United Kingdom (UK) of between $100-200$ per $100,000 .{ }^{1}$ Significant disability develops after a mean of eight years disease duration. ${ }^{2-9}$ The cause of MS is unknown, although the evidence suggests MS is a complex disease with various contributing factors involved in risk. $^{10}$

Epidemiological studies of MS prevalence and incidence suggest that ethnicity may be a risk factor for the development of MS. Both MS incidence and prevalence is significantly higher among White people compared to people of other ethnicities. ${ }^{11-}$

${ }^{15}$ The lowest country-level prevalence rates have been reported in countries with very small proportions of White people such as Japan $(7.7 / 100,000)$ and Iran $(32 / 100,000)$, whereas the highest rates are in countries with predominantly White populations, such as Norway $(151 / 100,000)$ and the UK $(203 / 100,000) \cdot{ }^{1,16-19}$ What is more, in countries where there is a mix of local-born White and local-born nonWhite residents, MS risk is almost always higher amongst White residents. ${ }^{11-15,19-21}$

However, definitive studies to confirm a causal link between ethnicity and MS do not exist. The epidemiological work referred to above may be driven not by genetic differences, but by differing environmental exposures and behaviours. Current hypotheses incorporate genetics to varying extents, such as: (i) mostly genetics 


\section{Methods}

The geographical area to calculate prevalence of MS was defined as the catchment area of the three nearest Clinical Commissioning Groups (CCG). These three are Tower Hamlets, Newham and City \& Hackney, which correspond to the innermost boroughs in the east of London. Together they are referred to here simply as 'east London', highlighted in Figure 1. 
Data for both pwMS and the baseline population were extracted from a 2013 anonymised general practice (GP) based patient records database. The GP database was accessed for this study by the Clinical Effectiveness Group (KB) of Barts and The London School of Medicine \& Dentistry. The GP database records all patients registered with a GP using the 'EMIS' electronic patient records system. The total number of patients represents the 'baseline population'. All patients coded with 'MS' represent the total number of pwMS. Data were grouped into 5-year agegroups and stratified by sex, ethnicity and CCG. Data from four GP practices in east London that do not use EMIS could not be included in this study.

MS prevalence rates were standardised for age using the direct method based on the 2013 European Standard Population, and expressed as $n / 100,000 .^{27}$ All prevalence rates reported here are age-standardised, unless otherwise specified. Using Microsoft Excel we calculated the overall MS prevalence rate, and specific MS prevalence rates stratified by sex and three ethnic groups: White, Black and South Asian. These ethnic groups are aggregates of standard ethnic classifications in the UK Census, which are used for self-classification on EMIS. 'White' includes Caucasian people such as those of British, American and European descent; 'Black' includes people of African and Caribbean descent; and 'South Asian' includes people of Indian, Bangladeshi, Pakistani and Sri Lankan descent. Because of smallcounts once divided into age, sex and ethnicity, $95 \%-$ Confidence intervals were calculated at $95 \%$ confidence using the normal binomial method for proportionsa Poisson 
distribution. Upper and lower bounds were calculated for each age-group to allow

for direct age standardisation.

\section{Results}

A total of 907,151 patients were registered with GP practices of east London. Of these, 776 had a diagnosis of MS. Table 1 shows a breakdown of this population by sex and ethnicity. Confidence intervals are not shown as each upper and lower limit was within 1 case per 100,000 from the estimate, using the normal binomial method of deriving $95 \%$ confidence intervals for proportions.

[Table 1 Placeholder]

The overall prevalence (per 100,000) of MS in east London was 111. For women prevalence was 152 and for men 70. The prevalence for MS in the White population was 180 , for Black people it was 74 , and for South Asians 29 . The sex ratios (female:male) were 2.2, 2.1 and 2.8, respectively. Figure 2 illustrates the sex and ethnicity-specific prevalence rates. Figures 3 and 4 illustrate the age-specific prevalence rates for each sex and ethnic group. Table 2 provides these rates, including $95 \%$ confidence intervals. In this table confidence intervals were derived using a Poisson distribution because many of the subgroups had fewer than 10 counts.

[Figure 2 Placeholder]

[Figure 3 Placeholder] 


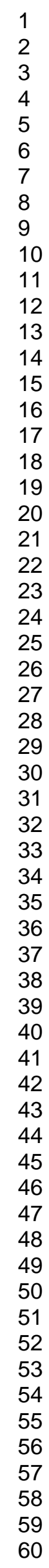

[Figure 4 Placeholder] 


\section{Discussion}

To our knowledge this is the first study reporting ethnicity-specific prevalence of MS in east London. The overall prevalence of MS we detected was slightly lower than in a recent UK-wide study. ${ }^{1}$ Due to the limited sample size our prevalence rates at the extreme ends of the age spectrum are unreliable (see Table 2). Nevertheless, the prevalence peaks for the White population are virtually identical to those reported for the entire UK. ${ }^{1,28}$ We also calculated the incidence rates of MS by ethnicity using new cases in the year up to date we used to calculate prevalence rates. Differences in incidence by ethnicity roughly mirrored prevalence differences at Incidence rates per 100,000 (with Poisson distribution-derived 95\% confidence intervals in brackets) were estimated at $8.6(5.7-12.4) / 100,000$ for White people, $6.2(2.8-11.7) / 100,000$ for Black people, and 3.7 (1.8-6.7) $/ 100,000$ South Asians. The relative differences in incidence by ethnicity appear similar to our reported prevalence differences, however as indicated by overlapping confidence intervals around our incidence estimates these differences are not statistically significant. Confidence intervals were Poisson distribution-derived because of small numbers of incident cases. Also dDue to small numbers, these incidence rates are not age-adjusted.

\section{Ethnicity-specific MS risk in the UK and the US}

The relative risks by ethnicity in this study are in line with previous findings in the UK from the 1970s which indicated that ethnic minorities have a lower MS risk than White people. ${ }^{13,14}$ In one of these studies conducted in London, the incidence for Black people was about $16 \%$ that of White people, whilst the incidence for Indian 
men and women was $26 \%$ and $6 \%$ that of White men and women. ${ }^{13}$ In another study based in London and the Midlands, the incidence for Black people and South Asians combined was $13 \%$ that of White people. ${ }^{14}$

Interestingly the findings in UK studies (including ours) for Black people are in contrast to findings from two recent studies US studies. One of these studies detected a higher incidence in Black compared to White military veterans. ${ }^{11}$ The other, which investigated members of the Kaiser Permanente managed care consortium in California, had similar findings. ${ }^{12}$ One possible explanation for the high MS risk in Black people in the US is selection bias in these studies, but other explanations to consider are genetic, environmental or behavioural differences between Black people in the US and the UK. Further work is needed in this area.

\section{MS Prevalence in Africa and South Asia}

What remains striking is the difference in MS prevalence between Black people and South Asians living in temperate climates compared to those living in their territorial ancestry. Even the highest prevalence reported for any sub-Saharan African country, $0.24 / 100,000$ in Ghana, is a small fraction of the prevalence of MS in Black people in east London $(74 / 100,000) .{ }^{29}$ The difference between the prevalence of MS in South Asians living in east London $(29 / 100,000)$ and, for example, people living in India $(7 / 100,000)$ or Pakistan $(5 / 100,000)$, is also impressive. ${ }^{29}$ 


\section{Limitations}

The dataset on which our analysis is based has been derived from a system designed for clinical use by GPs. It is possible that pwMS may have been missed in the system. Residents who register with a GP outside of the catchment area, will inevitably be missed. A study of MS prevalence in Wales used a more extensive method for case ascertainment that overlapped multiple data sources. ${ }^{28}$ In that study, the most comprehensive case source was GP records, which is equivalent to the source we relied on in our study. GP records covered $73 \%$ of all cases, with only hospital records contributing a significant proportion of additional cases. A previous study by the same group had similar case ascertainment. ${ }^{32}$ In terms of diagnostic accuracy, the more recent Welsh study found that less than $2 \%$ had unclear diagnoses, which 
is a testament to the reliability of GP records. Extrapolating from these studies, by only using GP records we are unlikely to have included misdiagnosed MS cases. However, we are likely to have underestimated prevalence estimates by approximately a quarter. Nevertheless, there appears to be little risk for biases in data by ethnicity as proportions of ethnic groups for pwMS in the east London GP database are very similar to the Barts MS Database, as such our relative comparisons between ethnicities are likely to be reliable. Once further developed, the Barts MS Database will be used in our future studies to account for missed pwMS and allow for diagnostic validation.

Our findings must be interpreted with caution when generalised to the rest of the UK, because of the risk of selection bias. It is possible that the Black and South Asian populations in east London are not representative when compared to the Black and South Asian population in the rest of the UK.

\section{Conclusion}

This is the first study on the ethnicity-specific prevalence of MS in east London. With its ethnic diversity in a region where the overall risk of MS is amongst the highest in the world this cohort of pwMS may contribute to further explore the geneenvironment interaction that ultimately determines the risk of developing MS, and the course of the disease.

[Table 2 Placeholder] 


\begin{abstract}
Acknowledgements
This work has been supported by a non-promotional educational grant from Novartis to QMUL (through KS). KS has been supported by a Higher Education Funding Council for England Clinical Senior Lectureship.
\end{abstract}

\title{
Disclosures
}

KS has received speaking honoraria from, and/or served on advisory boards for Novartis, Biogen, Teva, Merck-Serono and Merck Inc, has received support for attending an international conference from Genzyme and is a PI on studies sponsored by Novartis, Roche and Teva. 


\section{References}

1. Mackenzie IS, Morant S V, Bloomfield G a, MacDonald TM, O'Riordan J. Incidence and prevalence of multiple sclerosis in the UK 1990-2010: a descriptive study in the General Practice Research Database. J Neurol Neurosurg Psychiatry. 2014;85:76-84. doi:10.1136/jnnp-2013-305450.

2. Kaufman DW, Reshef S, Golub HL, et al. Survival in commercially insured multiple sclerosis patients and comparator subjects in the U.S. Mult Scler Relat Disord. 2014;3(3):364-371. doi:10.1016/j.msard.2013.12.003.

3. Tremlett $H$, Zhao $Y$, Rieckmann $P$, Hutchinson $M$. New perspectives in the natural history of multiple sclerosis. Neurology. 2010;74(24):2004-2015. doi:10.1212/WNL.0b013e3181e3973f.

4. Coles A, Deans J, Comptson A. Multiple sclerosis treatment trial precipitates divorce. J Neurol Neurosurg Psychiatry. 2001;70(1):135. doi:10.1136/jnnp.70.1.135.

5. Sadovnick A, Eisen K, Ebers G, Paty D. Cause of death in patients attending multiple sclerosis clinics. Neurology. 1991;41(8):1193-1196.

6. Morales-Gonzáles JM, Benito-León J, Rivera-Navarro J, Mitchell AJ, for. A systematic approach to analyse health-related quality of life in multiple sclerosis: the GEDMA study. Mult Scler. 2004.

doi:10.1191/1352458504ms967oa.

7. Jefferies K. The neuropsychiatry of multiple sclerosis. Adv Psychiatr Treat. 2006;12:214-220. doi:10.1192/apt.12.3.214.

8. Pfleger $\mathrm{CCH}$, Flachs EM, Koch-Henriksen N. Social consequences of multiple sclerosis (1): early pension and temporary unemployment--a historical prospective cohort study. Mult Scler. 2010;16(1):121-126. doi:10.1177/1352458509352196. 
9. Pfleger $\mathrm{CCH}$, Flachs EM, Koch-Henriksen N. Social consequences of multiple sclerosis. Part 2. Divorce and separation: a historical prospective cohort study. Mult Scler. 2010;16(7):878-882. doi:10.1177/1352458510370978.

10. Ramagopalan S V, Dobson R, Meier UC, Giovannoni G. Multiple sclerosis: risk factors, prodromes, and potential causal pathways. Lancet Neurol. 2010;9(7):727-39. doi:10.1016/S1474-4422(10)70094-6.

11. Wallin MT, Culpepper WJ, Coffman P, et al. The Gulf War era multiple sclerosis cohort: age and incidence rates by race, sex and service. Brain. 2012;135(Pt 6):1778-85. doi:10.1093/brain/aws099.

12. Langer-Gould A, Brara SM, Beaber BE, Zhang JL. Incidence of multiple sclerosis in multiple racial and ethnic groups. Neurology. 2013;80:1734-1739. doi:10.1212/WNL.0b013e3182918cc2.

13. Dean G, McLoughlin H, Brady R, Adelstein a M, Tallett-Williams J. Multiple sclerosis among immigrants in Greater London. Br Med J. 1976;1(April):861864. doi:10.1136/bmj.1.6014.861.

14. Dean G, Brady R, McLoughlin H. Motor neurone disease and multiple sclerosis among immigrants to Britain. Br J Prev Soc Med. 1977;31:141-147.

15. Taylor BV, Pearson JF, Clarke G, et al. MS prevalence in New Zealand, an ethnically and latitudinally diverse country. Mult Scler. 2010;16(12):14221431. doi:10.1177/1352458510379614.

16. Osoegawa M, Kira J, Fukazawa T, et al. Temporal changes and geographical differences in multiple sclerosis phenotypes in Japanese: nationwide survey results over 30 years. Mult Scler. 2008;15(2):159-173. doi:10.1177/1352458508098372.

17. Ebrahimi HA, Sedighi B. Prevalence of multiple sclerosis and environmental factors in Kerman province, Iran. Neurology Asia. 2013;18(4):385-389. 
18. Grytten N, Glad SB, Aarseth JH, Nyland H, Midgard R, Myhr K-M. A 50-year follow-up of the incidence of multiple sclerosis in Hordaland County, Norway. Neurology. 2006;66(2):182-186. doi:10.1212/01.wnl.0000195549.95448.b9.

19. Kingwell E, Marriott JJ, Jetté $\mathrm{N}$, et al. Incidence and prevalence of multiple sclerosis in Europe: a systematic review. BMC Neurol. 2013;13:128. doi:10.1186/1471-2377-13-128.

20. Smestad C, Sandvik L, Holmoy T, Harbo HF, Celius EG. Marked differences in prevalence of multiple sclerosis between ethnic groups in Oslo, Norway. $J$ Neurol. 2007;255(1):49-55. doi:10.1007/s00415-007-0659-8.

21. Kurtzke JF. Epidemiologic evidence for multiple sclerosis as an infection. Clin Microbiol Rev. 1993;6(4):382-427.

22. Schmidt H, Williamson D, Ashley-Koch A. HLA-DR15 Haplotype and Multiple Sclerosis: A HuGE Review. Am J Epidemiol. 2007;165(10):1097-1109. doi:10.1093/aje/kwk118.

23. Ramagopalan SV, Ebers GC. Genes for multiple sclerosis. Lancet. 2008;371:283-5. doi:10.1016/S0140-6736(08)60145-2.

24. Ramagopalan SV, Maugeri NJ, Handunnetthi L, et al. Expression of the Multiple Sclerosis-Associated MHC Class II Allele HLA-DRB1*1501 Is Regulated by Vitamin D. PLoS Genet 2009;5:e1000369. doi:10.1371/journal.pgen.1000369.

25. Simpson S, Blizzard L, Otahal P, Van der Mei I, Taylor B. Latitude is significantly associated with the prevalence of multiple sclerosis: a meta-analysis. J Neurol Neurosurg Psychiatry. 2011;82:1132-1141. doi:10.1136/jnnp.2011.240432.

26. Maruszak H, Brew BJ, Giovannoni G, Gold J. Could antiretroviral drugs be effective in multiple sclerosis? A case report. Eur J Neurol. 2011;18(9):110111. doi:10.1111/j.1468-1331.2011.03430.x. 
27. ONS. Revised European Standard Population 2013 (2013 ESP). Available at: http://www.ons.gov.uk/ons/guide-method/user-guidance/health-and-lifeevents/revised-european-standard-population-2013--2013-esp-/index.html. Accessed April 15, 2015.

28. Hirst C, Ingram G, Pickersgill $T$, Swingler R, Compston D a S, Robertson NP. Increasing prevalence and incidence of multiple sclerosis in South East Wales. J Neurol Neurosurg Psychiatry. 2009;80(4):386-91. doi:10.1136/jnnp.2008.144667.

29. MSIF. Atlas of MS 2013: Mapping Multiple Sclerosis Around the World. 2013. Available at: www.msif.org/wp-content/uploads/2014/09/Atlas-of-MS.pdf.

30. Benamer HTS, Shakir RA. The neurology map of the Arab world. Journal of the Neurological Sciences. 2009;285(1-2):10-12. doi:10.1016/j.jns.2009.05.012.

31. Owolabi MO, Bower JH, Ogunniyi A. Mapping Africa's way into prominence in the field of neurology. Arch Neurol. 2007;64(12):1696-1700. doi:10.1001/archneur.64.12.1696.

32. Swingler RJ, Compston DA. The prevalence of multiple sclerosis in south east Wales. J Neurol Neurosurg Psychiatr. 1988;51(12):1520-1524. 


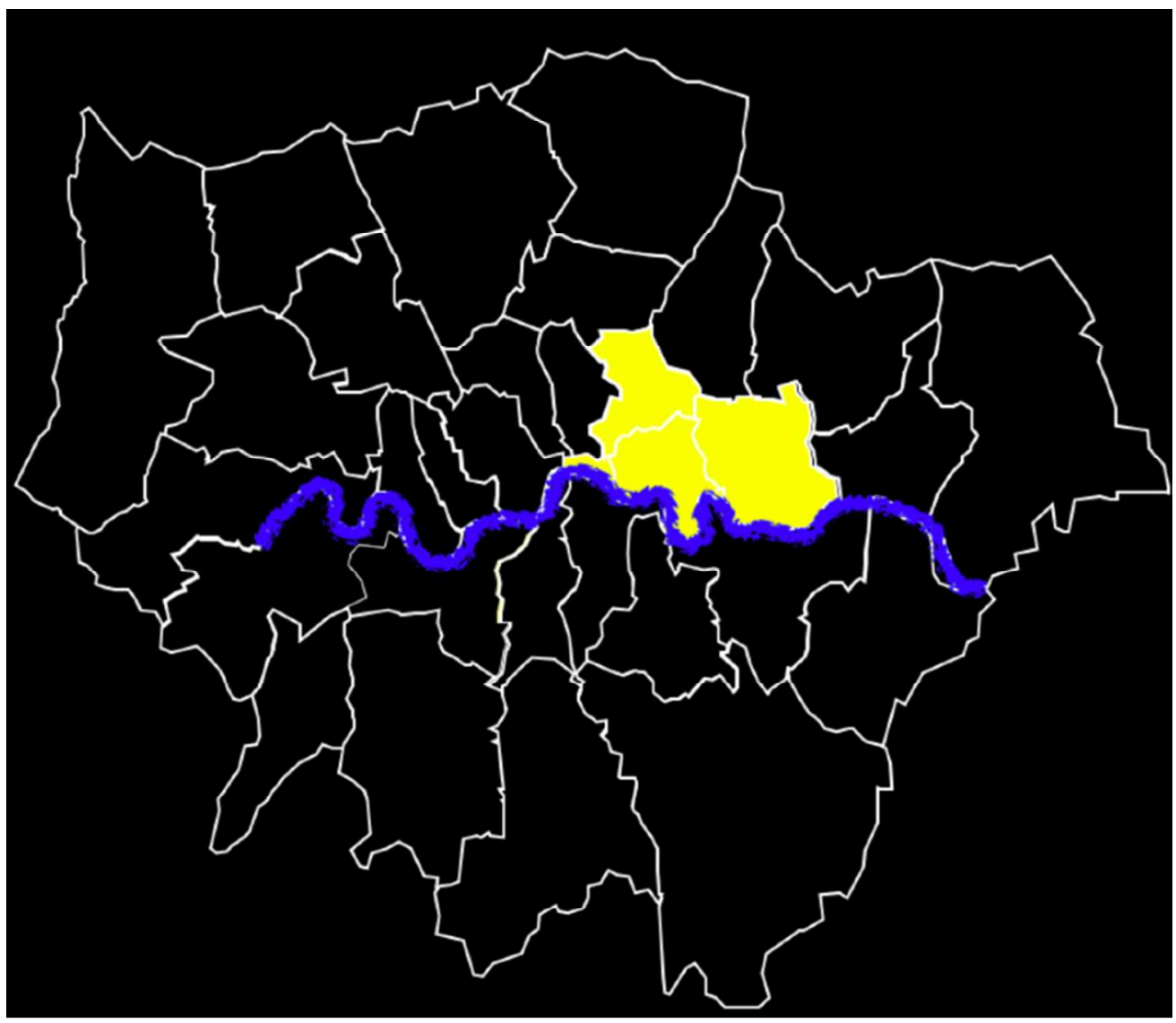

Figure 1. Map of London showing borough boundaries with 'east London' catchment area highlighted. $269 \times 232 \mathrm{~mm}(72 \times 72$ DPI $)$ 
Table 1. Numbers of people with multiple sclerosis registered in GP practices within inner East London, by sex and ethnicity

\begin{tabular}{|ll|c|l|}
\hline Ethnicity & Female & Male & Total \\
\hline White & 345 & 162 & 507 \\
Black & 77 & 34 & 111 \\
South Asian & 47 & 24 & 71 \\
Other & 15 & 9 & 24 \\
Unknown & 38 & 25 & 63 \\
\hline Total & $\mathbf{5 2 2}$ & $\mathbf{2 5 4}$ & $\mathbf{7 7 6}$ \\
\hline
\end{tabular}


1

2

3

4

5

6

7

8

9

10

11

12

13

14

15

16

17

18

19

20

21

22

23

24

25

26

27

28

29

30

31

32

33

34

35

36

37

38

39

40

41

42

43

44

45

46

47

48

49

50

51

52

53

54

55

56

57

58

59

60

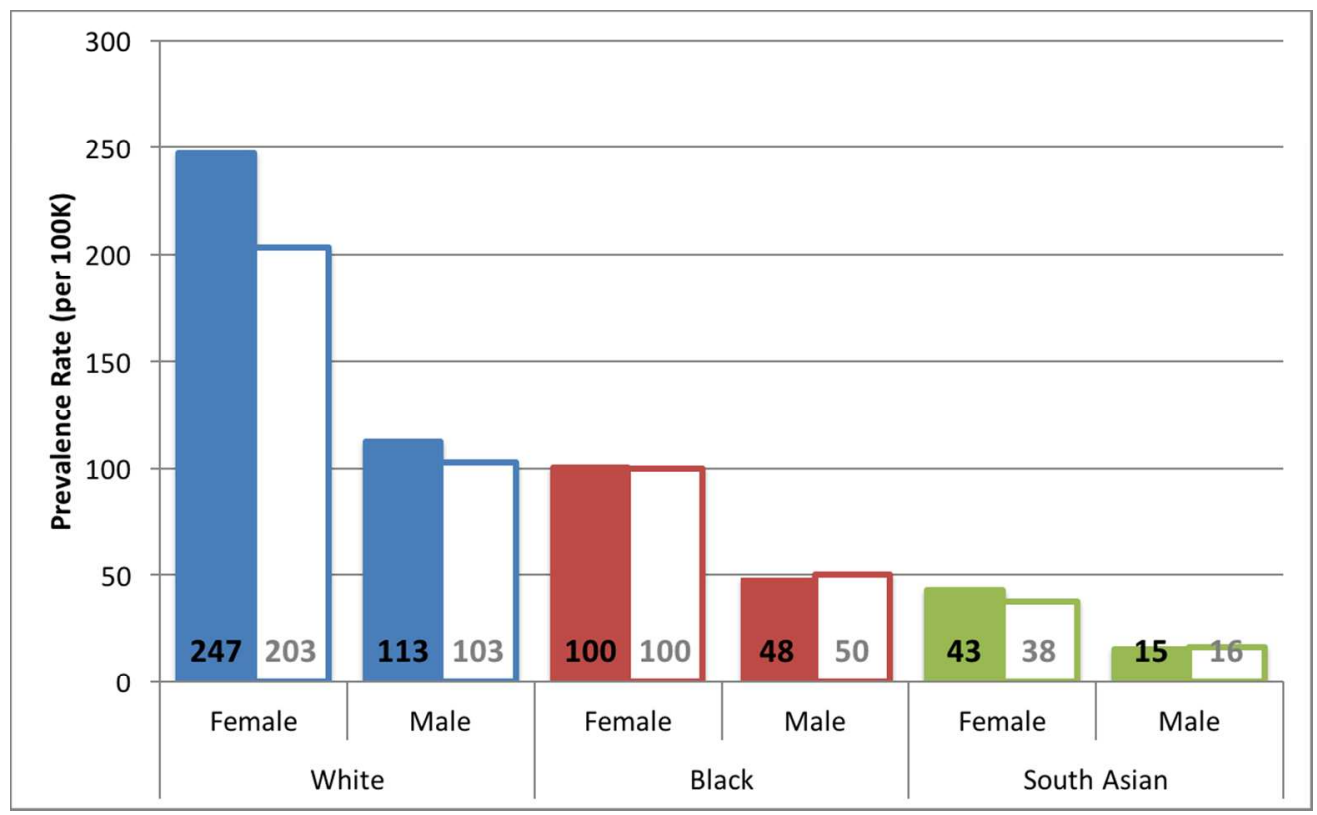

Figure 2. Ethnicity-specific MS Prevalence: Crude (white bars) and Age-Standardised (filled bars). $213 \times 131 \mathrm{~mm}(150 \times 150 \mathrm{DPI})$ 


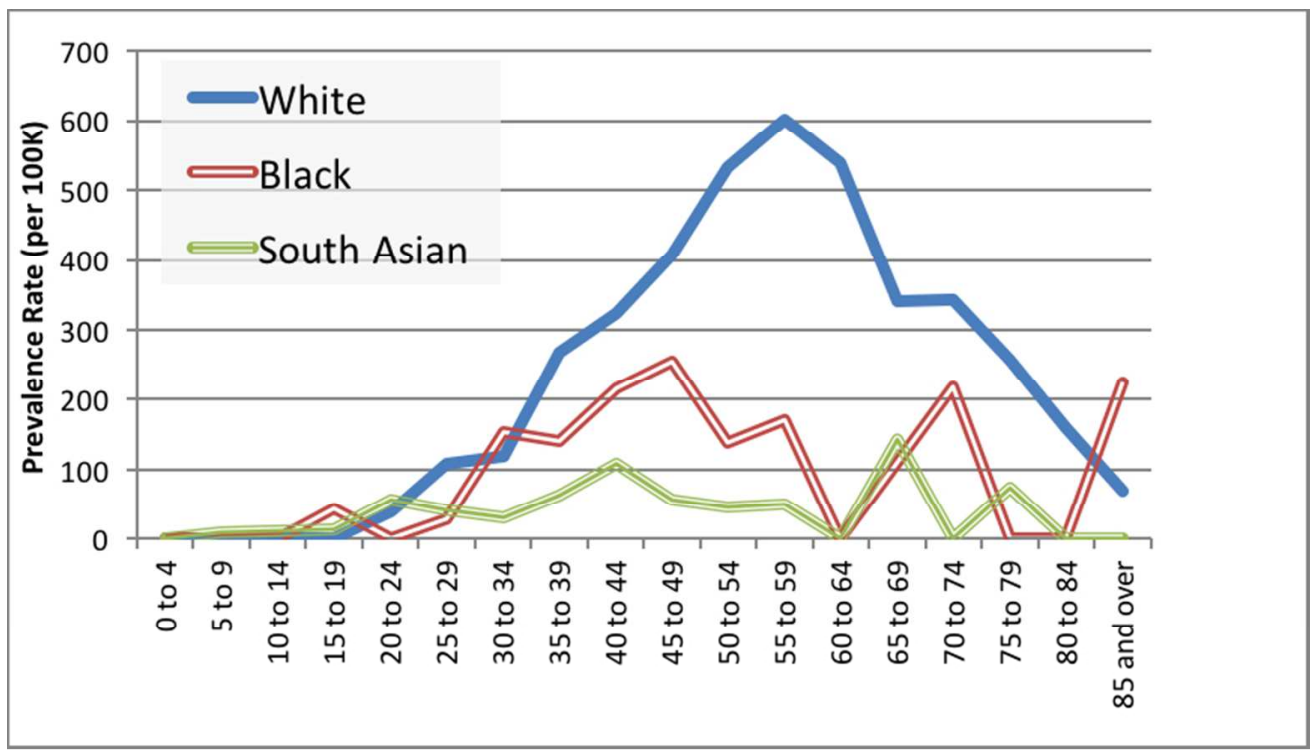

Figure 3. MS Prevalence for Women by Age, Stratified by Ethnicity $146 \times 83 \mathrm{~mm}(150 \times 150 \mathrm{DPI})$ 
Page 23 of 23

Multiple Sclerosis Journal

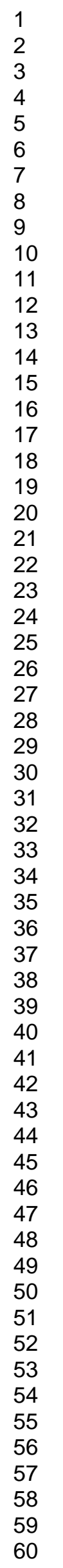

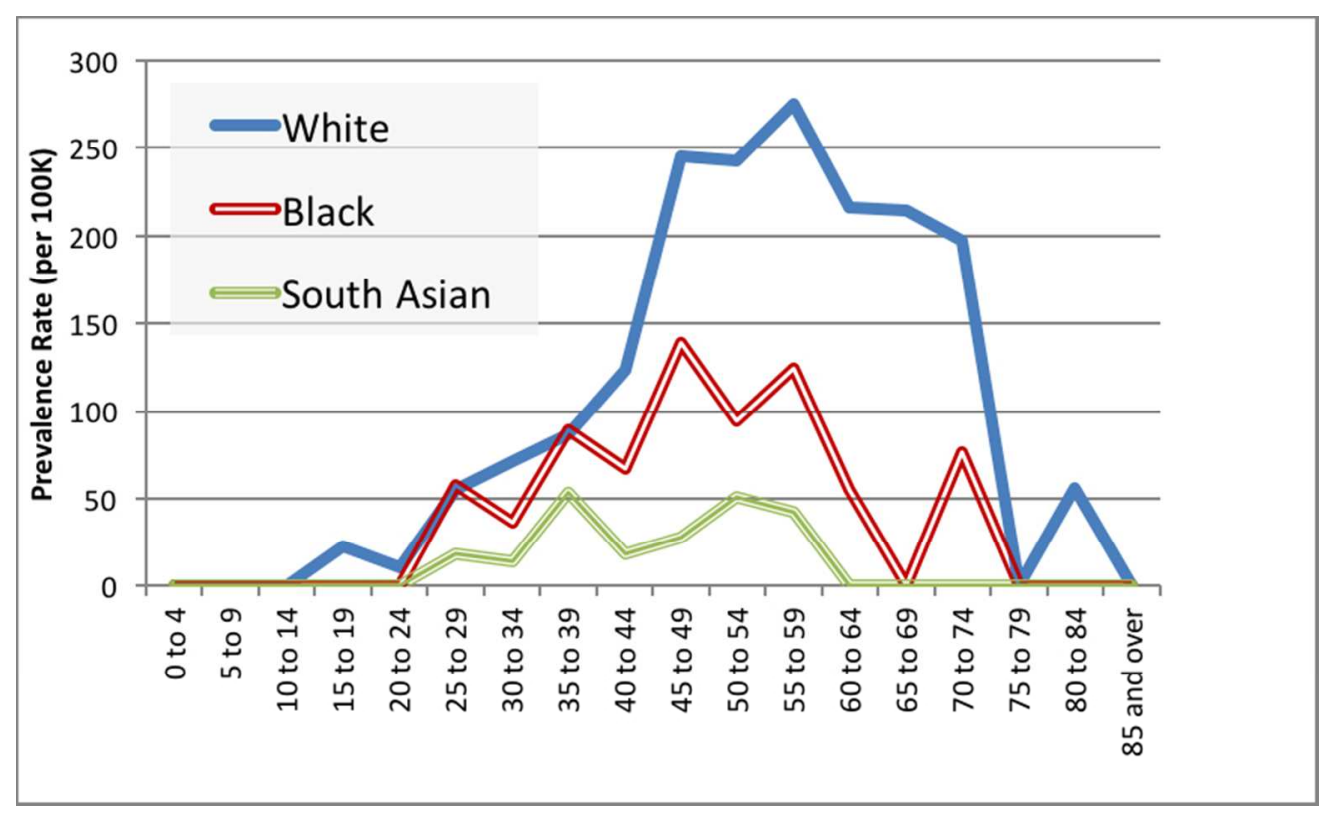

Figure 4. MS Prevalence for Men by Age, Stratified by Ethnicity $146 \times 89 \mathrm{~mm}(150 \times 150 \mathrm{DPI})$

http://mc.manuscriptcentral.com/multiple-sclerosis 
Table 2. Standardised prevalence rates (per 100,000) for each age group, specific to sex and ethnicity, including $95 \%$ confidence intervals*

\begin{tabular}{|c|c|c|c|c|c|c|c|c|c|}
\hline \multirow[b]{3}{*}{ Age } & \multirow{3}{*}{$\begin{array}{l}\text { Female } \\
\text { White } \\
\text { Rate }\end{array}$} & \multirow{2}{*}{\multicolumn{2}{|c|}{$\begin{array}{l}\text { 95\% Confidence } \\
\text { Interval }\end{array}$}} & \multirow{3}{*}{$\begin{array}{c}\text { Female } \\
\text { Black } \\
\text { Rate }\end{array}$} & \multirow{3}{*}{\multicolumn{3}{|c|}{$\begin{array}{l}\text { Female } \\
\text { South } \\
\text { Asian } \\
\text { Rate }\end{array}$}} & \multirow{2}{*}{\multicolumn{2}{|c|}{$\begin{array}{l}\text { 95\% Confidence } \\
\text { Interval }\end{array}$}} \\
\hline & & & & & & & & & \\
\hline & & Lower & Upper & & & & & Lower & Upper \\
\hline 0 to 4 & 0.0 & 0.0 & 1.7 & 0.0 & 0.0 & 2.8 & 0.0 & 0.0 & 1.3 \\
\hline 5 to 9 & 0.0 & 0.0 & 2.5 & 0.0 & 0.0 & 2.9 & 0.5 & 0.0 & 2.8 \\
\hline 10 to 14 & 0.0 & 0.0 & 3.9 & 0.0 & 0.0 & 3.8 & 0.7 & 0.0 & 3.6 \\
\hline 15 to 19 & 0.0 & 0.0 & 3.2 & 2.4 & 0.3 & 8.8 & 0.7 & 0.0 & 3.9 \\
\hline 20 to 24 & 2.4 & 0.9 & 5.2 & 0.0 & 0.0 & 3.3 & 3.4 & 1.2 & 7.3 \\
\hline 25 to 29 & 6.5 & 4.4 & 9.1 & 1.7 & 0.2 & 6.1 & 2.5 & 1.0 & 5.1 \\
\hline 30 to 34 & 7.8 & 5.3 & 11.0 & 10.0 & 5.0 & 17.9 & 2.0 & 0.6 & 4.7 \\
\hline 35 to 39 & 18.7 & 13.5 & 25.3 & 9.9 & 4.5 & 18.8 & 4.4 & 1.8 & 9.1 \\
\hline 40 to 44 & 22.7 & 15.9 & 31.4 & 15.1 & 8.2 & 25.3 & 7.6 & 3.3 & 14.9 \\
\hline 45 to 49 & 28.6 & 20.3 & 39.1 & 17.8 & 10.6 & 28.2 & 3.9 & 0.8 & 11.5 \\
\hline 50 to 54 & 37.3 & 27.2 & 49.9 & 9.7 & 4.2 & 19.2 & 3.2 & 0.4 & 11.4 \\
\hline 55 to 59 & 39.0 & 28.0 & 52.9 & 11.1 & 4.1 & 24.3 & 3.3 & 0.4 & 11.8 \\
\hline 60 to 64 & 32.4 & 22.0 & 45.9 & 0.0 & 0.0 & 8.4 & 0.0 & 0.0 & 5.4 \\
\hline 65 to 69 & 18.7 & 10.7 & 30.4 & 6.1 & 0.7 & 22.1 & 7.8 & 1.6 & 22.8 \\
\hline 70 to 74 & 17.2 & 8.9 & 30.0 & 11.0 & 3.0 & 28.0 & 0.0 & 0.0 & 7.9 \\
\hline 75 to 79 & 10.3 & 4.4 & 20.3 & 0.0 & 0.0 & 8.6 & 2.9 & 0.1 & 16.4 \\
\hline 80 to 84 & 4.0 & 1.1 & 10.2 & 0.0 & 0.0 & 9.7 & 0.0 & 0.0 & 10.8 \\
\hline \multirow[t]{2}{*}{85 and over } & 1.7 & 0.2 & 6.3 & 5.6 & 0.1 & 31.3 & 0.0 & 0.0 & 18.4 \\
\hline & $\begin{array}{c}\text { Male } \\
\text { White }\end{array}$ & \multicolumn{2}{|c|}{$\begin{array}{l}\text { 95\% Confidence } \\
\text { Interval }\end{array}$} & $\begin{array}{l}\text { Male } \\
\text { Black }\end{array}$ & \multicolumn{2}{|c|}{$\begin{array}{c}\text { 95\% Confidence } \\
\text { Interval }\end{array}$} & $\begin{array}{l}\text { Male } \\
\text { South } \\
\text { Asian }\end{array}$ & \multicolumn{2}{|c|}{$\begin{array}{l}\text { 95\% Confidence } \\
\text { Interval }\end{array}$} \\
\hline Age & Rate & Lower & Upper & Rate & Lower & Upper & Rate & Lower & Upper \\
\hline 0 to 4 & 0.0 & 0.0 & 1.6 & 0.0 & 0.0 & 2.7 & 0.0 & 0.0 & 1.2 \\
\hline 5 to 9 & 0.0 & 0.0 & 2.4 & 0.0 & 0.0 & 2.9 & 0.0 & 0.0 & 1.5 \\
\hline 10 to 14 & 0.0 & 0.0 & 3.9 & 0.0 & 0.0 & 3.7 & 0.0 & 0.0 & 1.9 \\
\hline 15 to 19 & 1.2 & 0.0 & 6.8 & 0.0 & 0.0 & 3.8 & 0.0 & 0.0 & 2.1 \\
\hline 20 to 24 & 0.6 & 0.0 & 3.5 & 0.0 & 0.0 & 4.1 & 0.0 & 0.0 & 1.3 \\
\hline 25 to 29 & 3.3 & 1.7 & 5.8 & 3.5 & 0.7 & 10.2 & 1.1 & 0.3 & 2.8 \\
\hline 30 to 34 & 4.6 & 2.7 & 7.4 & 2.4 & 0.3 & 8.5 & 0.9 & 0.2 & 2.7 \\
\hline 35 to 39 & 6.1 & 3.4 & 10.0 & 6.3 & 2.0 & 14.6 & 3.7 & 1.6 & 7.3 \\
\hline 40 to 44 & 8.7 & 5.0 & 14.1 & 4.7 & 1.3 & 12.0 & 1.3 & 0.2 & 4.6 \\
\hline 45 to 49 & 17.2 & 11.3 & 25.0 & 9.7 & 4.4 & 18.4 & 2.0 & 0.2 & 7.1 \\
\hline 50 to 54 & 17.0 & 10.6 & 25.7 & 6.6 & 2.2 & 15.5 & 3.6 & 0.7 & 10.5 \\
\hline 55 to 59 & 17.9 & 10.9 & 27.6 & 8.1 & 2.2 & 20.7 & 2.8 & 0.3 & 10.0 \\
\hline 60 to 64 & 13.0 & 6.9 & 22.2 & 3.3 & 0.1 & 18.4 & 0.0 & 0.0 & 6.7 \\
\hline 65 to 69 & 11.8 & 5.9 & 21.1 & 0.0 & 0.0 & 13.8 & 0.0 & 0.0 & 11.4 \\
\hline 70 to 74 & 9.9 & 3.6 & 21.5 & 3.8 & 0.1 & 21.2 & 0.0 & 0.0 & 9.4 \\
\hline 75 to 79 & 0.0 & 0.0 & 5.1 & 0.0 & 0.0 & 9.4 & 0.0 & 0.0 & 8.2 \\
\hline 80 to 84 & 1.4 & 0.0 & 7.8 & 0.0 & 0.0 & 11.2 & 0.0 & 0.0 & 8.9 \\
\hline 85 and over & 0.0 & 0.0 & 5.6 & 0.0 & 0.0 & 22.4 & 0.0 & 0.0 & 21.4 \\
\hline
\end{tabular}

